\title{
Prescription Adaptation Services: A Win for Patients and Providers
}

Alex J. Adams, PharmD, MPH

Former Executive Director, Idaho State Board of Pharmacy; Current Administrator, Idaho Division of Financial Management

\begin{abstract}
"Prescription adaptation services" (PAS) refers to the ability of pharmacists "to adapt an existing prescription when, in the ir professional judgment, the action is intended to optimize the therapeutic outcome of treatment." If structured appropriately, PAS can provide a benefit in enhancing the timeliness of patient care, while reducing the administrative burden on both physicians and pharmacists. Moreover, it leverages the strengths of both health professions, specifically the medication expertise of pharmacists. Unfortunately, in most states it will require a change in regulations in order to enable PAS.
\end{abstract}

"Prescription adaptation services" (PAS) refers to the ability of pharmacists "to adapt an existing prescription when, in their professional judgment, the action is intended to optimize the therapeutic outcome of treatment." ${ }^{1}$ In essence, adaptation occurs when a pharmacist modifies an existing prescription issued by another licensed practitioner in order to improve patient care. As such, PAS may be key to reducing the significant administrative burdens that physicians and pharmacists face on the frontlines that ultimately delay patient care.

\section{Examples of Burdens and Delays in Practice}

Consider a case in which a physician prescribes Ventolin ${ }^{\circledR}$. The patient presents the prescription to the pharmacy, the pharmacist adjudicates the claim with the patient's health plan, and the claim is denied because ProAir ${ }^{\circledR}$ is the health plan's preferred albuterol inhaler. In order to dispense Ventolin ${ }^{\circledR}$ as prescribed, prior authorization is needed from the plan. The pharmacist calls the physician's office to ascertain their preferred next step, but because a conversation between the pharmacist and physician is unlikely to occur in real time, the patient leaves the pharmacy empty handed and will have to make a second trip to the pharmacy once the matter is resolved. Unfortunately, primary medication non-adherence rates are such that some patients may never return. ${ }^{2}$

Many similar examples abound:

- $\quad$ Prescribers may select a package size for a cream that is not commercially available.

- A patient may be on vacation and left their blood pressure medication at home.

- A prescriber may have inadvertently left off a quantity on a medication that is taken daily and is generally written in increments of a 30-day supply.

- A patient may prefer a liquid formulation of a drug instead of the capsule.

Corresponding Author: Alex J. Adams, PharmD, MPH Former Executive Director, Idaho State Board of Pharmacy Current Administrator, Idaho Division of Financial Management Email: AlexAdamsRPh@gmail.com
In each case, the end result is the same: the pharmacist cannot act without contacting the prescriber and obtaining their consent, no matter how commonsense the situation. In addition, the patient is left waiting without their needed medication.

Complications at the pharmacy counter are, in part, why leading national medical associations have all called for efforts to reduce the excessive administrative burdens that physicians face. ${ }^{3-5}$ One study found the average physician spends 8.7 hours per week on administrative work, which resulted in lower career satisfaction. ${ }^{6}$ One study estimated physicians spend more than 60 minutes each day addressing prescription issues, with an estimated cost to the medical practice of \$5-\$7 per pharmacy call. ${ }^{7}$ A study of primary care practices logged 567 clarification calls over a two week period, primarily related to prior authorizations (37\%), formulary issues (26\%), and unclear/missing dosages $(21.7 \%){ }^{8}$ The same study found $34 \%$ of the problems were not resolved on the same day even when an acute medication was involved. ${ }^{8}$

Such issues are similarly burdensome to pharmacists. Community pharmacists reported spending $8 \%$ and $6 \%$ of their work week communicating with other health care providers from independent and chain settings, respectively. ${ }^{9}$ These pharmacists reported this time as a major barrier to good care, with one pharmacist lamenting the "time wasted" between the pharmacy, physician, and insurance. ${ }^{9}$

\section{Role for Prescription Adaptation Services}

This is where PAS, if structured appropriately, can really provide a benefit in enhancing the timeliness of patient care, while reducing the administrative burden on both physicians and pharmacists. Moreover, it leverages the strengths of both health professions, specifically the medication expertise of pharmacists.

Unfortunately, in most states it will require a change in regulations in order to enable PAS. Privately, some pharmacists will confide they already practice in this manner as it is in the best interest of patient care, but state law generally delineates what must be on a prescription in order for it to be valid, and 
limits the authority of pharmacists to make deviations from a prescription as ordered without prior prescriber consent.

Canadian provinces are much farther ahead than U.S. states with respect to enabling PAS; in Canada, the allowed PAS typically fall into two categories: 1) Renewals; and 2) Changes (e.g., changes to dispensing quantity, formulation, route of administration, complete missing information, and therapeutic substitutions). ${ }^{10}$

In its first year of operation in British Columbia, pharmacists performed 96,890 adaptations. ${ }^{11-12}$ Continuation of therapy renewals were the most frequent adaptation (79.5\%), followed by changes in dose $(7.2 \%)$, formulation $(4.9 \%)$, regimen $(4.5 \%)$, and therapeutic substitutions (3.8\%). ${ }^{10}$ Initially, physician feedback on adaptation services in Canada was generally negative. ${ }^{13}$ Despite these initial concerns, pharmacists noted that support increased in subsequent years, with the number of "do not adapt" prescriptions decreasing over time. ${ }^{14}$ The uptake of PAS has been small relative to the total number of prescriptions filled, but each adaptation represents a potential optimization in patient care. In addition, the 96,890 adaptations performed in the first year in British Columbia may have saved 96,890 calls between pharmacists and prescribers, leading to more efficient and timely care for patients.

For U.S. regulators to enable PAS, learning from the experience of Canadian provinces can be beneficial. The Idaho State Board of Pharmacy recently underwent a process to change its regulations to a "standard of care approach" that removes many prescriptive regulations with a goal of empowering pharmacists to practice to the top of their education and training. ${ }^{15}$ In so doing, the Idaho board enabled PAS for both renewals and certain changes. A summary of the Idaho regulations are enclosed in Table 1 as a potential starting point for other jurisdictions. ${ }^{16}$

Given the efficiency gains and commonsense nature of PAS, the Idaho regulations encountered little opposition. Some patient advocacy groups representing the mental health community expressed concern about how therapeutic substation could apply to psychotropic medications, a concern that has been raised in other jurisdictions. ${ }^{17-18}$

The hallmark of Idaho's PAS is retaining prescriber and patient choice. ${ }^{19}$ If a prescriber wants a patient on a specific medication or formulation, the prescriber can always request that the prescription be "dispensed as written" or a similar designation. Similarly, patients have to opt-in to accepting the change in prescription, retaining the patient's autonomy in their own health care decisions.

\section{Conclusion}

PAS offers a rare win-win-win. Patients can receive their optimized medications sooner. Prescribers and pharmacists are better leveraged, and their administrative burden is reduced.
Moreover, health plans benefit from enhanced formulary compliance without burdening their provider network. Additional jurisdictions may consider PAS as structured in Canada or Idaho as they pursue their own regulatory updates in the years ahead.

\section{Funding Support: None}

Conflicts of Interest: None

Disclaimer: The views expressed in this manuscript are those of the authors alone, and do not necessarily reflect those of the employer.

Acknowledgments: None

\section{References}

1. College of Pharmacists of British Columbia. Orientation Guide: Professional Practice Policy \#58 Medication Management (Adapting a Prescription). http://library.bcpharmacists.org/6_Resources/62_PPP/1017-PPP58_OrientationGuide.pdf (Accessed June 13, 2020)

2. Adams AJ, Stolpe SF. Defining and Measuring Primary Medication Nonadherence: Development of a Quality Measure. J Manag Care Spec Pharm. 2016;22(5):516523. https://doi.org/10.18553/jmcp.2016.22.5.516

3. Lagasse J. ACP calls for continued efforts in reducing excessive physician administrative burden.

HealthcareFinance. June 15, 2018. Available from: https://www.healthcarefinancenews.com/news/acpcalls-continued-efforts-reducing-excessive-physicianadministrative-burden (Accessed June 13, 2020)

4. Murphy K. Administrative Burden Remains Top Challenge for Physicians. EHR Intelligence. March 31, 2017. Available from:

https://ehrintelligence.com/news/administrativeburden-remains-top-challenge-for-physicians

(Accessed June 13, 2020)

5. American Academy of Family Physicians (AAFP). AAFP Sustains Fight to Reduce Administrative Burden for Family Medicine. Available from: https://www.aafp.org/media-center/kits/aafpsustains-fight-to-reduce-administrative-burden-forfamily-medicine.html (Accessed June 13, 2020)

6. Woolhandler S, Himmelstein DU. Administrative work consumes one-sixth of U.S. physicians' working hours and lowers career satisfaction. Int J Health Serv. 2014;44(4):635-42.

7. Injured Workers Pharmacy. Solving the Prescription Nightmare: How physicians are regaining control and cutting costs. Available:

https://www.iwpharmacy.com/sites/default/files/doc uments/White\%20Paper_Solving\%20the\%20Prescript ion\%20Nightmare.pdf (Accessed June 13, 2020) 
8. Hansen LB, Fernald D, Araya-Guerra R, et al. Pharmacy Clarification of Prescriptions Ordered in Primary Care: A Report from the Applied Strategies for Improving Patient Safety (ASIPS) Collaborative. JABFM. 2006;19(1):24-30.

9. AmerisourceBergen. Pharmacy Check-Up: Activities and Barriers to Care Analysis. October 2018. Available from:

https://www.amerisourcebergen.com/abcnew//media/assets/amerisourcebergen/pharmacycheckup/abc-pharmacy-checkupsurvey_final.pdf?la=en\&hash=B5F4B9FA91979759F4 6F7307C23FFC87EBB735B7 (Accessed June 13, 2020)

10. Adams AJ. Prescription Adaptation Services: A Regulatory and Practice Perspective. Ann Pharmacother. 2018;52(7):700-703. doi: 10.1177/1060028018763883.

11. Marra C, Lynd L, Grinrod, et al. An Overview of Pharmacy Adaptation Services in British Columbia. Available from:

https://www2.gov.bc.ca/assets/gov/health/healthdrug-

coverage/pharmacare/coreadaptationoverview.pdf (Accessed June 13, 2020)

12. Marra CA, Lynd LD, Grinrod KA, et al. Evaluating the labour costs associated with pharmacy adaptation services in British Columbia. Canadian Pharmacists Journal. 2012;145(2):78-82.

13. Henrich N, Joshi P, Grinrod K, et al. Family Physicians' Perceptions of Pharmacy Adaptation Services in British Columbia. Canadian Pharmacists Journal. 2011;144(4):172-178.
14. Grinrod KA, Lynd LD, Joshi P. Pharmacy Owner and Manager Perceptions of Pharmacy Adaptation Services in British Columbia. Canadian Pharmacists Journal. 2011;144(5):231-235.

15. Adams AJ. Transitioning Pharmacy to "Standard of Care" Regulation: Analysis of How Pharmacy Regulates Relative to Medicine and Nursing. Research in Social and Administrative Pharmacy. 2018. DOI: 10.1016/j.sapharm.2018.10.008

16. Idaho Administrative Code. Rules of the Idaho State Board of Pharmacy. Available from: https://adminrules.idaho.gov/rules/current/27/2701 01.pdf (Accessed June 13, 2020)

17. Moran M. Assembly Responds to Arkansas Law on "Therapeutic Substitution." Psychiatric News. August 5, 2016. Available from: https://psychnews.psychiatryonline.org/doi/full/10.1 176/appi.pn.2016.PP8a2 (Accessed June 13, 2020)

18. Vanderholm T, Klepser D, Adams AJ. State Approaches to Therapeutic Interchange in Community Pharmacy Settings: Legislative and Regulatory Authority. J Manag Care Spec Pharm. 2018;24(12):1260-1263. Heeps://doi.org/10.18553/jmcp.2018.24.12.1260

19. Adams AJ, Chopski NL. Rethinking pharmacy regulation: Core elements of Idaho's transition to a "Standard of Care" approach. J Am Pharm Assoc. NovDec 2020;60(6):e-109-e-112.

doi:10.1016/j.japh.2020.07.013 
Table 1. Sample PAS Regulations from Idaho

\begin{tabular}{|c|c|c|}
\hline $\begin{array}{l}\text { Type of } \\
\text { Adaptation }\end{array}$ & \begin{tabular}{|l} 
Rule \\
Number
\end{tabular} & Regulation $^{16}$ \\
\hline Renew & 402.03 & $\begin{array}{l}\text { "A prescription drug order may be refilled when permitted by state and } \\
\text { federal law and as specifically authorized by the prescriber. A pharmacist } \\
\text { may also refill a prescription for a non- controlled drug when the prescriber } \\
\text { is not available for authorization." }\end{array}$ \\
\hline $\begin{array}{l}\text { Change - } \\
\text { Quantity }\end{array}$ & 403.01 & $\begin{array}{l}\text { "A pharmacist may change the quantity of medication prescribed if: } \\
\text { a. The prescribed quantity or package size is not commercially available; } \\
\text { b. The change in quantity is related to a change in dosage form; } \\
\text { c. The change is intended to dispense up to the total amount authorized by } \\
\text { the prescriber including refills; or } \\
\text { d. The change extends a maintenance drug for the limited quantity } \\
\text { necessary to coordinate a patient's refills in a medication synchronization } \\
\text { program." }\end{array}$ \\
\hline $\begin{array}{l}\text { Change - Dosage } \\
\text { Form }\end{array}$ & 403.02 & $\begin{array}{l}\text { "A pharmacist may change the dosage form of the prescription if it is in the } \\
\text { best interest of patient care, so long as the prescriber's directions are also } \\
\text { modified to equate to an equivalent amount of drug dispensed as } \\
\text { prescribed." }\end{array}$ \\
\hline $\begin{array}{l}\text { Change - } \\
\text { Complete Missing } \\
\text { Information }\end{array}$ & 403.03 & $\begin{array}{l}\text { "A pharmacist may complete missing information on a prescription if there is } \\
\text { sufficient evidence to support the change." }\end{array}$ \\
\hline $\begin{array}{l}\text { Change- } \\
\text { Therapeutic } \\
\text { Substitution }\end{array}$ & 404.05 & $\begin{array}{l}\text { "A pharmacist may substitute a drug with another drug in the same } \\
\text { therapeutic class provided the patient opts-in and the substitution lowers } \\
\text { the cost to the patient or occurs during a drug shortage." }\end{array}$ \\
\hline
\end{tabular}

